\title{
Community Schools and the Role of University-School-Community Collaboration
}

\author{
Kathleen Provinzano, Ryan Riley, Bruce Levine, and Allen Grant
}

\begin{abstract}
Public school districts are locally controlled and funded through local property taxes. Funding schools this way perpetuates structural inequities in poorer school districts and as a result, students living in poverty have minimal access to critical resources that support student learning. Community schools are resurfacing in many of these urban spaces as a mechanism for addressing the systemic and structural inequities plaguing students, schools, and communities. Advocates posit that increasing student achievement requires addressing the needs of the whole child; conceptualizing schooling through this lens offers an expanded vision of what public education needs to be for many of today's children. This paper aims to improve our overall understanding of community schools and highlights specific actions taken by community organizations and higher education institutions to create meaningful partnerships with public schools operating as community schools. The authors posit that collaborative and organically developed, grassroots relationships have the potential to alter the traditional dynamic between internal public school employees and external stakeholders, leading to school, student, and community transformation.
\end{abstract}

Keywords: Community partnerships; integrated student supports; school-community transformation

\section{Introduction}

Quality education has the potential to promote social and economic mobility for some of the nation's most disenfranchised students. Unfortunately, not all systems are equal and worse yet, equitable. Affluent parents have access to schools and resources that children on the lower end of the economic spectrum do not, creating a growing divide academically and in the long-term, economically (Garland, 2013). The quality of education students receive largely influences their occupational choices and subsequent income level (Hochschild, 2003). Fortunately, evidence suggests that high-quality schools are enough to significantly increase academic achievement among the poor (Dobbie \& Fryer, 2011), making it more likely for students to pursue postsecondary educational opportunities and improve their life trajectories. This is particularly salient for schools advancing a community-focused approach, because they mindfully address the effects of poverty and other out-of-school factors that contribute to gaps in student learning and achievement (Fehrer \& Leos-Urbel, 2016). Full service community schools provide children with equitable learning opportunities, manifested through a strategy that addresses the needs of the whole child. Students and families receive a comprehensive, integrated, and coordinated range of academic, health, and social/emotional services that supports improved outcomes for underserved children.

Metropolitan Universities Vol. 29 No. 2 (May 2018), DOI: 10.18060/21762 
Currently, there are over 5,000 community schools operating across 44 states and the District of Columbia, serving over five million students, and the numbers continue to grow (Coalition for Community Schools, n.d.). Given the increasing popularity of community school initiatives as a community and education reform strategy, it is important for community-based organizations (CBOs) and institutions of higher education (IHEs) to improve their overall understanding of community schools and the services they provide. By doing so, they are better suited to offer resources to scale such initiatives. The purpose of this article is twofold; the authors provide a description of what a community school is. A detailed example follows of how researchers from one institution of higher education (Drexel University), and one community-based organization (Communities in Schools Pennsylvania) created a meaningful partnership to support a community school initiative in Pennsylvania. This information was part of a presentation given at the Coalition of Urban and Metropolitan Universities (CUMU) 2017 Annual Conference in Denver, Colorado.

\section{What Are Community Schools and Why Do We Need Them?}

Carefully designed educational programs with comprehensive school facilities are oftentimes absent in high-poverty school systems serving economically disadvantaged areas (Min, Anderson, \& Chen, 2017). Deteriorating physical spaces, lack of relevant technology, and dated instructional resources are some of the challenges these schools face. As such, students attending under-resourced schools do not have the same opportunities to thrive academically and socially as their more advantaged peers. Reforming public schools and their surrounding communities continues to be a central strategy for mitigating the effects of poverty on students' well-being and academic performance in school (Biag \& Castrechini, 2016). Scholars and practitioners posit that schools offering direct services to address the needs of the whole child have a far greater influence on students' ability to perform well in school (Ladd, 2012) than singular reform initiatives situated in standards and standardization.

Not a new phenomenon, community schools are resurfacing in urban communities as a mechanism for addressing the multitude of challenges high-poverty schools and communities face. These schools leverage partnerships between the local school and community, and positively alter relationships between the school, families, and the community, more generally (Fehrer \& Leos-Urbel, 2016). Large-scale community school initiatives are occurring in Chicago, Tulsa, and Oakland, and the mayors of New York City and Philadelphia have publically pledged support for scaling community schools in their respective cities (Fehrer \& Leos-Urbel, 2016). Furthermore, recently enacted federal law (Every Student Succeeds Act [ESSA], 2015) includes the Full Service Community Schools program and other important provisions that advance community school strategies. Moreover, the law includes accountability measures that extend beyond academics and supportive programs such as the $21^{\text {st }}$ Century Community Learning Centers and the Promise Neighborhoods (Roche, 2015).

Although a step in the right direction, more is required to support these types of endeavors. It is important to capitalize on the rare, bipartisan compromise ESSA rendered and for policymakers and reform advocates to reconfigure what an equitable education looks like, and community schools are just the strategy to do this. The Coalition for Community Schools describes a community school as: 
Both a place and a set of partnerships between the school and other community resources. Its integrated focus on academics, health and social services, youth and community development, and community engagement leads to improved student learning, stronger families, and healthier communities. Children and families have an array of supports from community partners' right at their school. Communities and schools leverage their shared physical and human assets to help kids succeed (www.communityschools.org).

Working from this definition, the authors delved deeper into conceptualizing the ultimate purpose of education and identified how equity fits within that context. We view equity from the vantage point of student learning and development, as opposed to scores on high-stakes testing, or accountability. Jordan (2010) stipulated that given the "overlapping and intersecting social policy arenas that affect education, the educational system cannot be fixed from within" (p.157). Instead, broad-based approaches that address the overall needs of children (health, social/emotional, expanded learning), and the community must take the lead. The community school reestablishes the school as the center of the community. It provides community residents access to programs and services they otherwise do not have. Community schools embody an equity strategy, removing barriers negatively influencing the well-being of students and families. The services offered give students and families' opportunities, thus addressing the larger inequitable systems they contend with on a daily basis.

According to Angus (2009), it is important for policy and reform movements to support "schools forming respectful linkages with their communities, and embedding themselves within them, if they are to make a positive difference for currently less advantaged young people” (p. 40). Growing recognition that problems occurring in distressed communities have direct implications on students, families, and schools served as the genesis for this piece. The authors posit that fullservice community schools can serve as the much needed, systems-wide reform aimed at engaging school and community resources. Such collaborative and mutually beneficial partnerships might promote student, family, and community development.

\section{Exemplar Community School Initiatives}

Community schools are operating across the United States and have been for well over a decade. Examples include, but are not limited to, The Children's Aid Society Community Schools, United Way Community Schools, and University Assisted Community Schools (see Bronstein \& Mason, 2016; Frankl, 2016; Lubell, 2011 for a comprehensive list of community school exemplars). Each is committed to improving educational outcomes for children by offering essential supports that promote learning and have an explicit focus on the relationship between the school and the community. Funding and operations unfold differently in each community school, and each emphasizes different implementation priorities. However, they do have a shared vision for what an equitable school looks like and offer learning opportunities for IHEs and CBOs interested in involving themselves in the work.

The Children's Aid Society

The Children's Aid Society (CAS) has had a longstanding relationship with the New York City Department of Education and currently operates twenty-two community schools throughout the 
city. Bronstein and Mason (2016) report that CAS community schools follow a lead agency model, with CAS "serving as both a provider and broker of supports, services, and opportunities" (p. 56). In lead agency models, the community partner serves as the lead agency, providing the school with a community school coordinator who works jointly with school leadership to coordinate and maximize the array of services and service organizations funneling into the school and the local community. The lead partner manages any additional partners. Children's Aid Society community schools place a heavy emphasis on parent-engagement programs, and provide in-school parent resource centers staffed by trained parent coordinators. The coordinators engage in outreach with other parents and offer adult education classes and leadership institutes. This level of collaboration offers parents opportunities to become "funds of knowledge” (Heers, Van Klaveren, Groot, \& Maassen van den Brink, 2016, p. 1023) in their community schools, and increases the presence and activity of those traditionally alienated from the school. Empowering parents to lead and train other groups of parents makes use of the cultural resources parents from different backgrounds bring into schools.

Each CAS community school looks different, but they all deem five critical elements necessary for success: (a) a strong instructional program; (b) solid professional capacity; (c) close parentcommunity-school ties; (d) a student-centered learning climate; and (e) leadership that drives change (http://www.childrensaidnyc.org/programs/community-schools). The Children's Aid Society, through the National Center for Community Schools, also serves as a technical assistance organization for districts, schools, and community partners engaged in the work of community schools.

\section{United Way Community Schools}

The United Way is involved in community schools in multiple ways throughout the United States. In some instances, the organization operates as a funder or intermediary organization and in others as a lead agency. The Coalition for Community Schools identified the United Way of Greater Lehigh Valley in Pennsylvania as an exemplar in their community school approach. The agency works with four school districts in the Lehigh Valley, providing a fulltime community schools director and agency support to each community school. Each United Way Community School coordinates on-site medical and dental services, school supplies, on-site vision services, a food bank, clothing closet, and housing resources to over 8000 students and their families, with a particular focus on increasing third grade reading scores, Kindergarten readiness, and successful high school transition (http://www.unitedwayglv.org/see-the-impact/education/communityschools).

\section{University Assisted Community Schools}

Pioneered by the Netter Center for Community Partnerships at the University of Pennsylvania, University Assisted Community Schools (UACS) engage with K-12 students in "community problem solving that is integrated into the school curriculum and extended day programs" (Lubell, 2011, p. 15). The program engages students and community members by offering their programs in West Philadelphia schools (https://www.nettercenter.upenn.edu/). Bronstein and Mason (2016) note that UACS provide the type of service linkage between schools and communities that enhances the quality of life in the community while simultaneously improving 
the teaching, research, and service at the university, a mutually beneficial partnership. There are numerous UACS programs operating throughout the nation and each have different needs and resources.

Exemplary community schools also exist at the district, city, county, and state levels across the United States. Frankl (2016) highlights the ongoing community school movements occurring in districts in Austin, TX, Baltimore, MD, the city of Portland and Multnomah County, OR, and in the state of Kentucky. Each of these sites report sustainable and transformational results.

While community school strategies take different implementation approaches, there are multiple whole-child, research based strategies that are common amongst them. Frankl (2016) stated that effective community school initiatives offer culturally relevant curricula, including project-based learning that tackles community-specific issues, and high-quality teaching that utilizes student data and choice to guide instructional decision-making. Students and families also receive wraparound services offered before, during, and after school to help develop personal competencies. Teachers and administrators adhere to positive discipline practices that include restorative justice techniques, and engage in authentic parent and community engagement that provides leadership and adult education opportunities for families. Finally, community schools operate under the mantra of inclusive school leadership. At the helm of a community school is a principal who embraces leadership actions of students, families, and community members. The principal understands the importance of giving essential stakeholders a voice in decision-making that influences the scaling of community school initiatives. Community schools implementing these strategies can reduce risky behavior, lower the dropout rate, and increase the academic performance of their students (Heers et al., 2016).

Conceptualizing community schools as equity strategies will transform the local school and neighborhood, and provide students in under-resourced places with opportunities that support their success. Obviously, this requires strong, collaborative partners. Community-based organizations (CBOs) and institutions of higher education (IHEs) see the local neighborhood school as the core institution for community engagement, and as such can provide them with resources to advance their coordinated work. The following section describes how two such separate entities came together to support the community school strategy in one Pennsylvania district.

\section{University and Community Based Organizations Partnering to Advance Community Schools: The Drexel-Communities in School Effort}

The Coalition of Urban and Metropolitan Universities (CUMU) 2017 Annual Conference, the Urban Advantage, provided the perfect venue for researchers from the School of Education at Drexel University and leaders from Communities in Schools Pennsylvania to present their coordinated efforts to create meaningful partnerships with public schools operating as community schools. The collaboration developed from a Drexel-sponsored research initiative in one Pennsylvania district, the Pennsylvania Community School District (PCSD). Communities in Schools Pennsylvania was serving as a lead partner for several schools in the district, and soon a synergistic relationship emerged. Preliminary results from the research study (discussed below) 
led to coordinated efforts to support and scale community schools across the district. Here are some lessons learned.

\section{Research Approach}

Researchers from the School of Education at Drexel University engaged in a multi-year, multisite case study across five community schools in a large urban district in south central Pennsylvania, the Pennsylvania Community School District (PCSD). The district has a longstanding commitment to community school development and implementation, hence the reasoning for its selection. The researchers sought to explore the community school phenomenon through an investigation of the relationships, both within the school, and between the school and outside partners. Drexel scholars emphasized the distribution of challenges and opportunities associated with community school implementation. Two research questions guided this study:

1. How are community schools implemented across five PCSD school sites?

2. In what ways are development and implementation efforts connected to systems-level goals for student and school improvement?

\section{Methodology}

Data collection began in July 2016 and is ongoing. The researchers relied largely on interviews from a purposeful sample of community school leadership, including the superintendent, five central office administrators, five building level principals, and five community school directors. Moreover, they completed interviews with teachers and representatives from nine community service organizations. In addition, the researchers conducted focus groups with two parent groups. They also collected district documents, including parent survey data, attendance and behavioral data, and teacher turnover data.

Data analysis is ongoing, however early themes related to the role of universities in supporting and scaling community school efforts emerged, and the authors discuss these findings below.

\section{PCSD Community Context}

The Pennsylvania Community School District (PCSD) is a large, urban school district, home to demographically diverse residents of different racial, ethnic, linguistic, and cultural groups. Over ninety-percent of students qualify as free or reduced lunch, and a majority of students identify as Hispanic (any race). According to the most recent Pennsylvania School Performance Profile data, the number of students receiving special education services at PCSD exceeds the state average. Furthermore, the number of English Language Learners (ELLs) at PCSD greatly exceeds the state average. The district is home to nineteen schools, five of which function as fullservice community schools (Washington Middle School, Adams Elementary School, Jefferson Elementary School, Madison Elementary School, and Monroe Elementary School).

Community school implementation varies across each of the five sites. Each school adapted the process to meet local context. The PCSD community schools did not emerge overnight. Most began as an after-school program led by a community partner (i.e. Boys and Girls Club, United 
Way), and scaled up overtime to include health and mental health services, food security programs, dental programs, adult training programs, and other comprehensive services to support and engage families. Participants estimate that it takes approximately seven years to fully implement and scale strategies that positively influence school climate and offer students the range of services needed to be successful in school.

Preliminary Finding Relevant to CUMU 2017: Gaps in Research and Evaluation of Community Schools

Commonalities regarding how universities can support and scale up community school initiatives emerged across all five sites, specifically in areas related to research and evaluation. Participants, namely the building administrators, expressed an interest in collaborating with faculty at institutions of higher education to coordinate evaluation efforts. Community school strategies encompass a wide array of services. Pinpointing how to measure their effectiveness on a host of indicators is incredibly challenging and the task may lie beyond the scope of the principal and community school director's workload or expertise. This is especially important in the current high-stakes testing era characterized by unrealistic accountability standards and dwindling funds. Furthermore, because full-service community schools rely on non-education funds, grants, and other nonprofit contributions, information related to their effectiveness is necessary for inclusion in future funding applications.

Although findings from the research are limited at this time, it is evident that high-quality research and evaluation of community school initiatives can serve as the mechanism for university researchers to engage with their local community schools. Each principal they interviewed, along with the superintendent of schools and the community school director, indicated funding was a real issue for community school implementation and scaling efforts, including evaluation. Faculty experts at IHEs should seize this opportunity to work closely with the school to develop evaluation plans, which could subsequently lead to published works advancing community school funding support. This is especially important in Pennsylvania, which lacks a fair funding formula. Pennsylvania ranks $46^{\text {th }}$ in the nation when it comes to the state's share of education funding. The state relies entirely too much on local funding for schools (Education Law Center, 2017). Frankl (2016) urges that policy related to community schools should "explicitly outline that any new schools function as community schools...or, that every school with a specified percentage of students below the poverty indicator receive funding for a community school director" (p. 10). For this to occur, IHEs have to engage in meaningful interactions with the local schools in their area.

Interacting with local schools in a mutually beneficial manner provides faculty at IHEs opportunities to conduct seminal research, evaluation, and policy development related to community schools. Faculty and school leadership can collaboratively identify particular areas of need, a critical step if the partnership is going to be meaningful and positive. Because community schools receive offers of assistance from various community partners, it is important for universities to work in tandem with district and school leadership to offer coordinated services that both entities find meaningful and relevant.

Communities in Schools Pennsylvania: Support from a CBO Communities in Schools (CIS) 
Pennsylvania serves as the lead agency in four PCSD community schools. The organization is committed to providing students with a community of support intended to empower them to stay in school. Each school has a school-based coordinator who connects students and families with community resources in the school. Through programming, and the work of a CIS coordinator, the organization leverages community resources that meet both the academic and non-academic needs of children in PCSD schools. According to Bronstein and Mason (2016), the primary elements of the CIS model include:

A site coordinator assessing the needs at the beginning of the year, the use of evidencebased community resources, a public health model with two levels of prevention/ intervention services, and a constant monitoring and adjustment over the course of the year to ensure service delivery is driving outcomes (p. 104).

Communities in Schools is dedicated to including integrated student supports into the school, making them a sound partner for a lead agency in community schools. The level of services offered adhere to the Early Warning Indicators to support students' success and situated in a three-tiered system (see Figure 1). Tier 1 are the school-wide services available to students to foster a positive school climate. They are short-term interventions provided on an as-needed basis. Examples include school-wide anti-bullying programming, or college and career events. Tier 2 services occur in a group setting with students who have common needs, attendance improvement programs or academic tutoring interventions, for example. Finally, CIS site coordinators case-manage students who receive Tier 3 services, and provided them with direct services such as academic interventions, behavioral interventions, and/or crisis interventions.

\section{THREE TIERS OF SUPPORT}

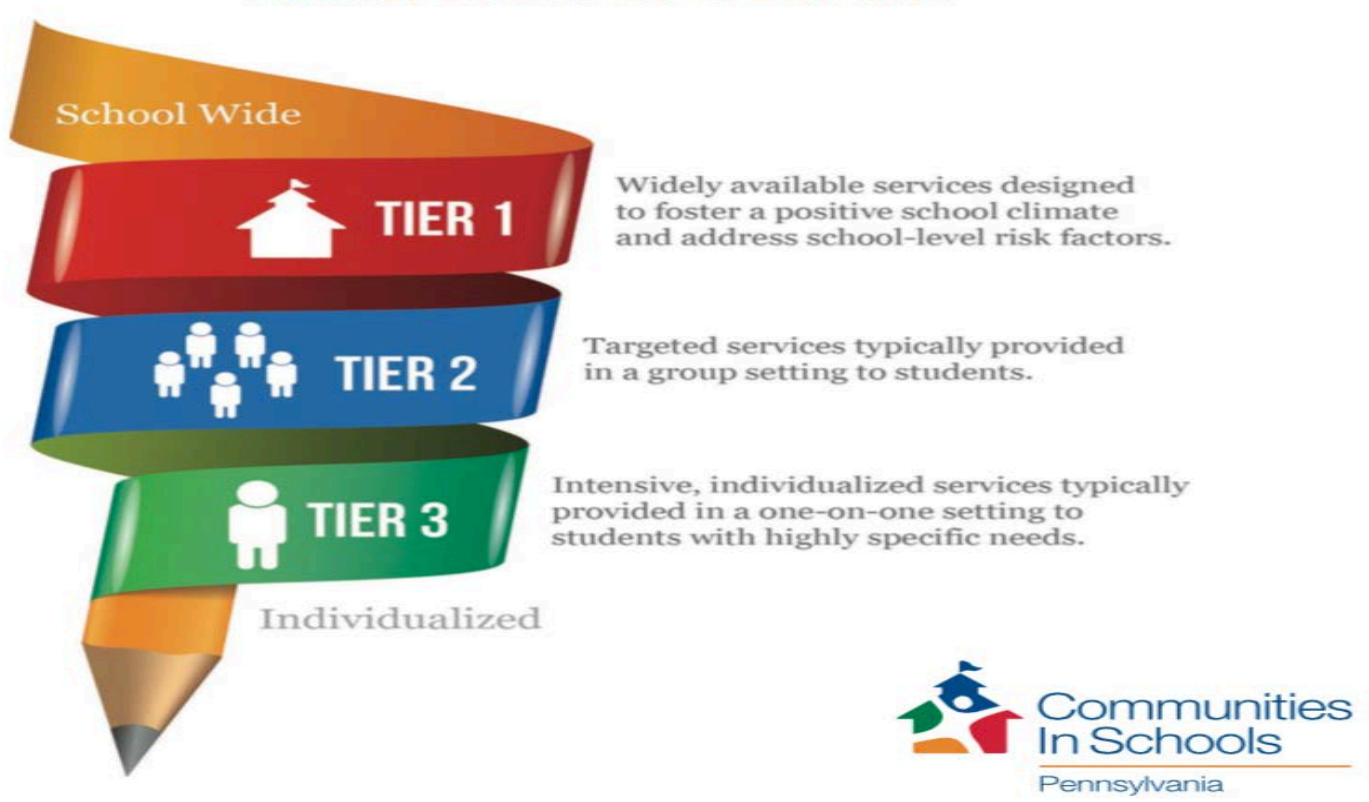

Figure 1: Communities in Schools (Pennsylvania) Model 
Drexel researchers and leadership from CIS continue to work together to uncover obstacles and challenges to community school initiatives in PCSD. For example, Drexel faculty found school leaders attributed a large part of the organic development of the community school with the work of community partners like CIS. Community-based organizations tend to have a stronger connection to the immediate needs of the community and serve as mediators between marginalized populations and institutionalized structures. This is particularly important in PCSD because most teachers and district employees live outside district boundaries. Prior to community school implementation, they had little presence in the community outside their respective schools. This in no way discredits the hard work and dedication of PCSD staff to their students and families. Rather, it calls attention to an overlooked fact relevant for schools looking to increase their level of engagement with parents and the surrounding community.

Annie, for example, a former community school director, stated that she needed to "create after school programs that were going to lure children and families into them." She emphasized that asking the kids and the parents was easy for her because she is a lifelong resident of the neighborhood. People trusted Annie in a way that they did not trust school employees at the time. This is important information for the district and CBOs to know as they develop parent and community engagement efforts. Sally, a current community school director, indicated that she and her principal are invested in efforts to shift staff's perspective about parent engagement and have been doing "a lot of work around understanding poverty, trauma, and racism because those are factors in what our students bring with them to school.” As these anecdotes demonstrate, a relationship between a community school, the community agency that supports it, and an institution of higher education wanting to evaluate it, leads to opportunities that support their respective agendas and their shared vision for advancing equitable community school approaches.

\section{Conclusion}

Accountability measures over the past two decades have primarily focused on school improvement efforts and outcomes, devoid of meaningful collaboration with community partners and families that target whole-child development. Collaboratively engaging with community schools at PCSD offered insight into how IHEs and CBOs can change the reform dialogue to one that advances genuine community partnerships, and supports a shared sense of responsibility for student success. Researchers from the School of Education at Drexel University and Communities in Schools Pennsylvania posit that community schools are a principal strategy for overcoming the devastating effects of poverty. IHEs and CBOs have an interest in supporting community schools in a way that makes the most sense for all involved. Communities in Schools as lead partner, coupled with concurrent research endeavors by faculty from the School of Education at Drexel University provided space for both entities to engage in meaningful collaboration focused on how to best support the community schools at PCSD. The partnership clearly advances individual (IHE, CBO, PCSD) interests, but more importantly it signifies the collective power groups have to advance shared short and long-term goals for community schools. 


\section{References}

Angus, L. (2009). Problematizing neighborhood renewal: Community school effectiveness and disadvantage. Critical Studies in Education, 50(1), 37-50.

https://doi.org/10.1080/17508480802526645

Biag, M., \& Castrechini, S. (2016). Coordinated strategies to help the whole child: Examining the contributions of full-service community schools. Journal of Education for Students Placed at Risk, 21(3), 157-175. https://doi.org/10.1080/10824669.2016.1172231

Bronstein, L.R., \& Mason, S.E. (2016). School-linked services: Promoting equity for children, families, and communities. New York, NY: Columbia University Press.

https://doi.org/10.7312/bron16094

Coalition for Community Schools (n.d.). Frequently asked questions about community schools. Washington, D.C. Retrieved from http://www.communityschools.org/aboutschools/faqs.aspx.

Dobbie, W., \& Fryer, R.G. (2011). Are high-quality schools enough to increase achievement among the poor? Evidence from the Harlem Children's Zone. American Economic Journal, 3(3), 187-217. https://doi.org/10.1257/app.3.3.158

Education Law Center (2017, March). Money matters in education justice: Addressing racial and class inequities in Pennsylvania's school funding system. Report prepared by the Education Law Center. Retried from https://www.elc-pa.org/wp-content/uploads/2017/03/Education-JusticeReport.pdf

Fehrer, K., \& Leos-Urbel, J. (2016). We're one team: Examining community school implementation strategies in Oakland. Education Sciences, 6(26), 1-24.

https://doi.org/10.3390/educsci6030026

Frankl, E. (2016, February). Community schools: Transforming struggling schools into thriving schools. Report prepared for the Center for Popular Democracy, Washington, D.C.

Garland, S. (2013, August). When class became more important to a child's education than race. The Atlantic. Retrieved from http://www.theatlantic.com/national/archive/2013/08/when-classbecame-more-important-to-a-childs-education-than-race/279064/

Heers, M., Van Klaveren, C., Groot, W., Maassen van den Brink, H. (2016). Community schools: What we know and what we need to know. Review of Educational Research, 86(4), 1016-1051. https://doi.org/10.3102/0034654315627365

Hochschild, J.L. (2003). Social class in public schools. Journal of Social Issues, 59(4), 821-840. https://doi.org/10.1046/j.0022-4537.2003.00092.x 
Jordan, W.J. (2010). Defining equity: Multiple perspectives to analyzing the performance of diverse learners. Review of Research in Education, 34, 142-178.

https://doi.org/10.3102/0091732X09352898

Ladd, H. (2012). Education and poverty: Confronting the evidence. Journal of Policy Analysis and Management, 31, 203-227. https://doi.org/10.1002/pam.21615

Lubell, E. (2011). Building community schools: A guide for action. Report prepared by the Children's Aid Society National Center for Community Schools. Retrieved from http://www.theoryofchange.org/wpcontent/uploads/toco_library/pdf/NCCS_BuildingCommunitySchools.pdf

Min, M., Anderson, J.A., \& Chen, M. (2017). What do we know about full-service community schools? Integrative research review using NVivo. School Community Journal, 27(1), 29-54.

Roche, M.K. (2015). New federal education law boosts community schools. Retrieved from http://www.communityschools.org/new_federal_education_law_boosts_community_schools/ 


\section{Author Information}

Kathleen Provinzano is an Assistant Professor in the Educational Administration program. Kathleen's teaching, research, and activism derive from her commitment to social justice and equitable, systems-level change across urban and rural landscapes. Understanding the synergistic relationship between teaching and scholarship, she believes in the importance of mentoring students as they engage in disciplined, reflective inquiry to address systemic problems plaguing their schools and communities. Her research interests include contextually responsive leadership, leadership for learning, and the historical, political, and socio-cultural context of schools and communities. Her work draws heavily from the intersectionality of class, race, and culture and she is currently investigating the influence of integrated supports on student learning and the school, parent, community dynamic in full-service community school settings.

* Kathleen Provinzano

Drexel University

3141 Chestnut Street

Philadelphia, PA 19104

Telephone: 215.895.6770

Email: ktp37@drexel.edu

Ryan Riley serves as the President and State Director of Communities In Schools of Pennsylvania and works in partnership with state and local elected officials, as well as community and business leaders to support and sustain services aimed at improving education across Pennsylvania. Prior to his current role, he was the Vice President for Development and Marketing at Easter Seals Serving Washington, DC, Maryland and Virginia as well as the Associate Vice President of Development and Alumni Relations at Harrisburg University of Science and Technology.

Ryan Riley

Communities in Schools Pennsylvania

1429 N. Third Street, Suite 201

Harrisburg, PA 17102

Telephone: 717-233-4330

Email:info@cisofpa.org

Based in Washington, DC, Bruce Levine enjoys living in the Nation's Capital and bringing to the School, perhaps, a slightly different perspective on education and urban matters. I think that is enhanced by the fact that I have lived several professional lives-practicing attorney, strategy consultant, and executive of several startups — before joining the faculty at Drexel.

Bruce Levine

Lafayette Tower, Suite 420

801 17th Street, N.W.

Washington, DC 20006 
215.571.3460

Telephone: 301.529 .8469

Email: bl63@drexel.edu

Dr. Allen Grant is an education change agent with a wide variety of experiences in K-12 and higher education. He has taught kindergarten, worked as a language instructor in Spain, consulted as an IB PYP expert, and has held a plethora of leadership positions across K-12 and higher education. He is the past Director of the Louisiana Virtual School and was policy expert and grants coordinator for the Louisiana Board of Elementary and Secondary Education. Grant is the Academic Head of the Department Policy, Organization and Leadership for the School of Education. Besides Drexel, Grant has worked at work at LSU, UMUC and the Southern University Virtual Learning Environment. His research interests center around emerging technologies, community school models and most anything dealing with K-12 virtual schooling.

\author{
Allen Grant \\ Associate Clinical Professor \\ Department Chair for Education Policy and Leadership Programs \\ One Drexel Plaza, Room 112 \\ 3025 Market St \\ Philadelphia, PA 19104 \\ Phone: 215.895.6232 \\ acg48@drexel.edu \\ * Corresponding author
}

